US Army Corps

of Engineers ${ }_{\circledast}$

Engineer Research and

Development Center

\title{
Predicting the Impact of Aqueous lons on Fate and Transport of Munition Compounds in the Environment
}

Timothy C. Schutt and Manoj K. Shukla

August 2021

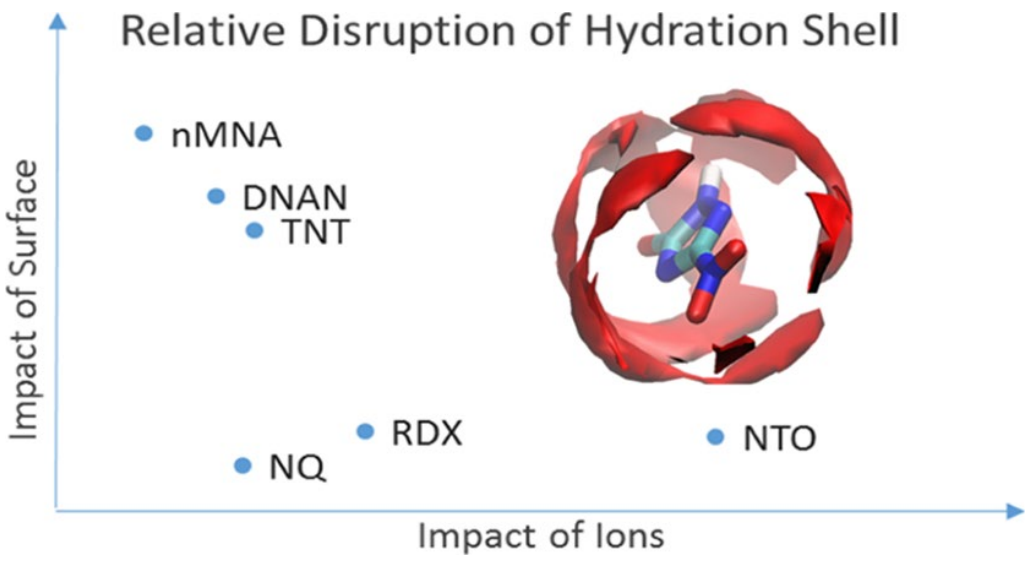


The U.S. Army Engineer Research and Development Center (ERDC) solves the nation's toughest engineering and environmental challenges. ERDC develops innovative solutions in civil and military engineering, geospatial sciences, water resources, and environmental sciences for the Army, the Department of Defense, civilian agencies, and our nation's public good. Find out more at www.erdc.usace.army.mil.

To search for other technical reports published by ERDC, visit the ERDC online library at https://erdclibrary.on.worldcat.org/discovery. 


\section{Predicting the Impact of Aqueous lons on Fate and Transport of Munition Compounds in the Environment}

Timothy C. Schutt and Manoj K. Shukla

Environmental Laboratory

U.S. Army Engineer Research and Development Center

3909 Halls Ferry Road

Vicksburg, MS 39180

Final report

Approved for public release; distribution is unlimited.

Prepared for U.S. Army Corps of Engineers

Washington, DC 20134

Under Environmental Security Technology Certification Program (ESTCP) 


\section{Preface}

This study was conducted for the U.S. Army Corps of Engineers (USACE) under the Environmental Quality Technology Program of the United States Army Corps of Engineers and the Environmental Security Technology Certification Program (ESTCP) of the Department of Defense.

The work was performed by the Engineer Research and Development Center, Environmental Laboratory (ERDC-EL). At the time of publication of this paper, the Deputy Director of ERDC-EL was Dr. Brandon Lafferty and the Director was Dr. Edmund J. Russo Jr.

This article was originally published in the Journal of Physical Chemistry on 9 May 2019. The authors would like to acknowledge editing and proof reading by colleagues Dr. Glen Jenness and Dr. Harley McAlexander for their aid in the preparation of this manuscript.

The Commander of ERDC was COL Teresa A. Schlosser and the Director was Dr. David W. Pittman.

DISCLAIMER: The contents of this report are not to be used for advertising, publication, or promotional purposes. Citation of trade names does not constitute an official endorsement or approval of the use of such commercial products. All product names and trademarks cited are the property of their respective owners. The findings of this report are not to be construed as an official Department of the Army position unless so designated by other authorized documents. 


\title{
Predicting the Impact of Aqueous lons on Fate and Transport of Munition Compounds in the Environment
}

\begin{abstract}
A model framework for natural water has been developed using computational chemistry techniques to elucidate the interactions between solvated munition compounds and eight common ions in naturally occurring water sources. The interaction energies, residence times, coordination statistics, and surface preferences of nine munitionrelated compounds with each ion were evaluated. The propensity of these interactions to increase degradation of the munition compound was predicted using accelerated replica QM/MM simulations. The degradation prediction data qualitatively align with previous quantum mechanical studies. The results suggest that primary ions of interest for fate and transport modeling of munition compounds in natural waters may follow the relative importance of $\mathrm{SO}_{4}{ }^{2-}, \mathrm{Cl}^{-} \gg \mathrm{HCO}_{3}{ }^{-}, \mathrm{Na}^{+}, \mathrm{Mg}^{2+}$ $>\mathrm{Ca}^{2+}, \mathrm{K}^{+}$, and $\mathrm{NH}_{4}^{+}$.
\end{abstract}

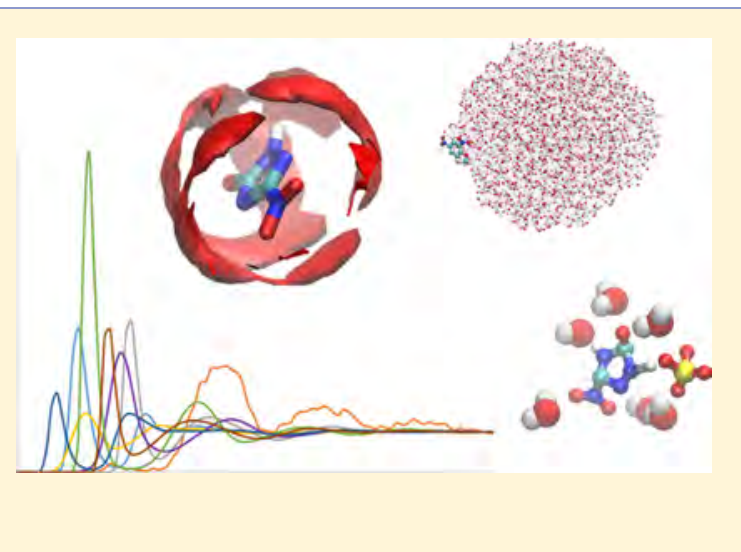

\section{INTRODUCTION}

Insensitive munition compounds (IMs) are of considerable interest for their improved safety and transportability over conventional explosives. ${ }^{1,2}$ However, detonation of rounds containing munitions for testing and training purposes may result in the deposition of residues around the training ranges. IMs tend to have significantly larger solubility in water compared to conventional explosives, and this increases their potential for transport through terrain. ${ }^{3}$ It is important to know the fate and transport of these materials as aspects of their impact on the environment are still being discovered. ${ }^{4-6}$

Because of the complexity in the number of degradation pathways and differences in soil and water compositions, the fate and transport of munition compounds in the environment remain difficult to predict. ${ }^{7}$ Nonequilibrium flow processes can be modeled by numerically solving complex systems of differential equations such as the HYDRUS model, ${ }^{8}$ but such approaches become increasingly difficult to characterize, parameterize, and evaluate when including realistic environmental complexities. The state-of-the-art environmental model for munition compounds, the Training Range Environmental Evaluation and Characterization System (TREECS) developed by Dortch et al., ${ }^{9}$ models the concentration of munition constituents in affluent waters from training sites (including time and use dependencies) to within order-of-magnitude accuracy compared with laboratory tests. Although this is a tremendous tool, further research is needed for many of the predictive test cases in their report as the levels of uncertainty of the predicted releases span both above and below regulated hazardous concentration benchmarks. ${ }^{9}$
The TREECS model and other environmental fate models require chemical descriptors for the soils and munition constituents that can be experimentally measured ${ }^{10}$ or predicted through quantum mechanical and molecular dynamics (MD) simulations. ${ }^{11}$ There exist many studies with detailed analysis of the degradation mechanisms for munition compounds in the environment. ${ }^{12-17}$ However, to reduce the complexity of the systems, environmental models are required to assimilate multiple mechanisms of degradation and transfer processes into combined empirical parameters causing a loss of fidelity in the prediction. It would be beneficial to link the molecular details with field-scale simulation software through standardized multiscale modeling networks; however, these practices are not yet established. ${ }^{18}$ The present work is directed at assimilating the molecular level details of munition compounds in natural water from MD simulations in a generalizable sense that still includes many specific ion-munition-water interactions.

\section{COMPUTATIONAL DETAILS}

2.1. General MD Parameters Employed. MD simulations were carried out in the Amber16 software package. ${ }^{19}$ The munition forcefields were based on GAFF parameters ${ }^{20,21}$ for the bond, angle, dihedral, and vdW terms, whereas the point charges were calculated with the RESP method as implemented in the antechamber. ${ }^{22}$ The underlying charge distribution was evaluated at the MP2 level of theory ${ }^{23}$ and the cc-pVTZ basis set $^{24}$ as implemented in Gaussian 16. ${ }^{25}$ The charges were not 
scaled down by the $80 \%$ factor typically applied ${ }^{20,26}$ to charges calculated at HF/6-31g level, as recent studies have shown good reproduction of dynamic properties' simple organic and ionic molecules using point charges calculated at the MP2/cc-pVTZ level. ${ }^{27-29}$ Water molecules were defined by the TIP4P-Ew model $^{30}$ in the MD simulations, and the GAFF ion forcefield files were chosen to match the water selection. ${ }^{31}$

Systems were built pairwise with all of the permutations of 1 ion (Figure 1) and 1 munition (Figure 2) accompanied by 1000

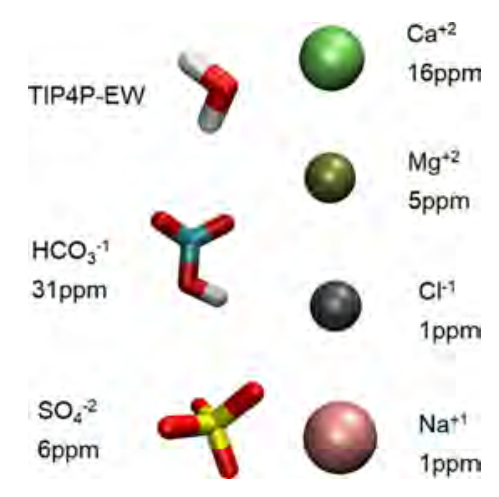

Figure 1. Natural water constituents and their concentrations used for the whole natural water simulations.

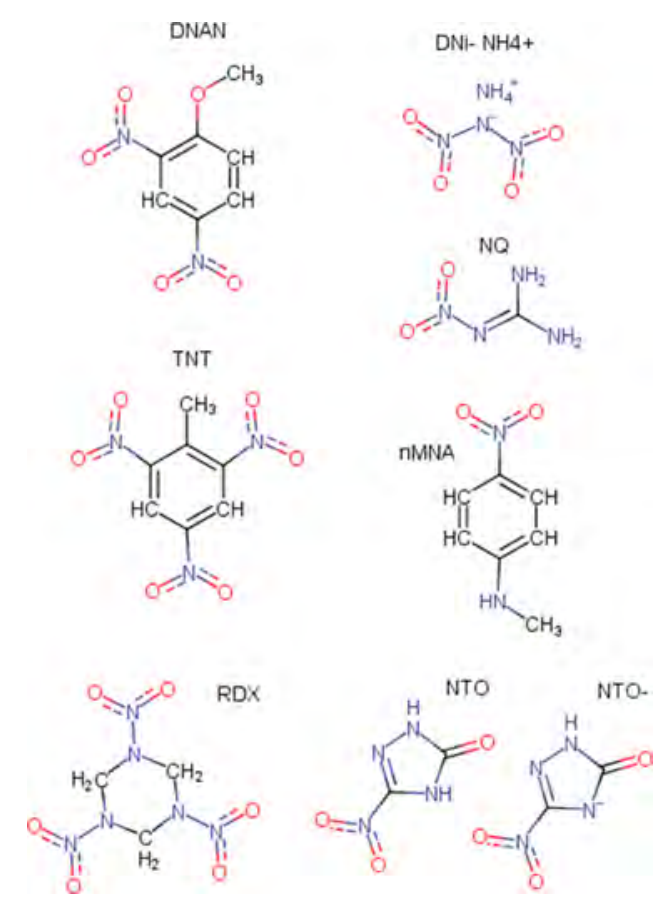

Figure 2. Defined structures for the munition compounds included in study. Acronym definitions for the munition compounds are as follows: DNAN-2,4-dinitroanisole; $\mathrm{NH}^{+} \mathrm{DNi}^{-}$-ammonium dinitramide; nMNA $-N$-methyl- $p$-nitroaniline; NQ-1-nitroguanidine; NTO-3nitro-1,2,4-triazol-5-one (neutral form); $\mathrm{NTO}^{-}$- conjugate base of NTO (anionic/deprotonated form); RDX-1,3,5-trinitro-1,3,5-triazinane; TNT-2,4,6-trinitrotoluene.

waters for quick calculation of pairwise trends in the dynamics. Each munition in pure water was simulated in the same way without any ions. In addition, systems were created for each munition compound in whole natural water with $100 \times$ concentrations (in order to increase sampling of ioninteractions) of each ion in Figure 1 and 10000 waters. Each
MD System was created in PACKMOL, ${ }^{32}$ converted to an amber file by tleap, and the coordinates minimized for 2000 steps of steepest descent followed by 2000 steps of conjugated gradient minimization in the Amber package. The minimized simulation boxes were equilibrated in the isobaric isothermal ensemble $(N P T)$ at $1 \mathrm{~atm}$ and $300 \mathrm{~K}$ for $1 \mathrm{~ns}$. The equilibrated systems were then simulated in the NVT ensemble at $300 \mathrm{~K}$ for the production runs where solvent orientation, interactions, and conformations with the munition compounds and ions were monitored. All MD simulations used a cutoff for the short-range electrostatic interactions of $10 \AA$ and the particle mesh Ewald algorithm for the long-range interactions. ${ }^{33}$ The temperature was held constant at $300 \mathrm{~K}$ by a Langevin thermostat with a collision frequency of $2 \mathrm{ps}^{-1}{ }^{34}$ The time step for all simulations was $1 \mathrm{fs}$, and the leapfrog algorithm was used for integrating the equations of motion. ${ }^{35}$

2.2. Umbrella Sampling. Umbrella sampling was performed to quantify the potential of mean force (PMF) between each ion and munition. Systems were created for each combination of one munition compound and one ion of the selected compounds and solvated by 1000 waters. Umbrella windows were defined every $0.2 \AA$ ranging from 2.5 to $9.9 \AA$ distance between the central atoms of each ion-munition pair. The umbrella potential was set to $7 \mathrm{kcal} \mathrm{mol}^{-1} \AA^{-2}$. Equilibration of each ion-munition pair at each distance was equilibrated for 250 ps starting from the nearest window's equilibrated coordinates, and the production run was for 500 ps. For the umbrella sampling simulations, the time step was increased to 2 fs and the Shake algorithm was used to maintain stability of the bonds with hydrogen atoms. ${ }^{36}$ The GPU-enabled pmemd.cuda_SPFP version of the amber engine was used for the umbrella sampling as it provided the fastest calculation under the simulation parameters and available hardware. Weighted histogram analysis method ${ }^{37}$ was employed to convert the logged restraint values into PMFs over the distance range. Block averaging was used to confirm convergence of the PMFs; the first half and second half of the production run produced PMF plots within $0.5 \mathrm{kcal} / \mathrm{mol}$ of each other.

2.3. Thermodynamic Integration. Amber's pmemd version of thermodynamic integration (TI) was employed with softcore potentials and 9 lambda values following the appropriate Gaussian quadrature and associated weighting values. Isobaric, non-isochoric constraints were used to allow for decreasing system size when modeling the "disappearance" of the munition from the solvated state. The change in potential with respect to lambda was monitored and integrated to evaluate the solvation energy of the munitions relative to the gas phase. Solvation energies for ionic compounds were high because of the lack of changing charge and protonation state that would accompany gas-phase versions of these munition compounds. The TI calculations were repeated 10 times for each munition compound, and the standard deviations in solvation energy were less than $10 \%$.

2.4. Quantum Mechanical/Molecular Mechanical. The quantum mechanical/molecular mechanical (QM/MM) implementation in Amber16 was used with PM6 representing the $\mathrm{QM}$ region and the same MD parameters as above for the MM region. The munition-ion pair and 6 nearest water molecules were treated with $\mathrm{QM}$, and the remaining water molecules were TIP3P MM molecules. ${ }^{31}$ Accelerated MD was used to boost low-energy configurations and thereby reduces energy barriers to conformational changes. These boosts permit greater sampling and increase the likelihood of thermal degradation 
modes allowing for observation of degradation within computationally accessible time scales. This method was developed by the McCammon group, ${ }^{38}$ implemented in Amber, ${ }^{16,19}$ and has been shown to accurately increase the sampling of $\mathrm{MD}$ systems. ${ }^{39}$ The threshold potential energy value for the system started at $1 \mathrm{kcal} / \mathrm{mol}$ per atom in the system and increased over 20 independent simulation runs at increasing boost levels by 0.1 $\mathrm{kcal} / \mathrm{mol}$ per atom in the system for each level and lasting over the 2 ns reactive production runs. These parameters were chosen to produce a good distribution of degraded and nondegraded systems. The individual contribution of each run to the likelihood of degradation was scaled by a Boltzmann expression of the boost energy level. The potential energy alpha coefficient was chosen to be $20 \%$ of the number of atoms in the system as recommended by the Amber16 user's manual. ${ }^{19}$ Additional boost on the dihedral potential was not used.

\section{RESULTS AND DISCUSSION}

The solvation energy of munition compounds was calculated in two steps, from bulk munition to gas phase and from gas phase to water-solvated; the summation of which provides the $\Delta G_{\text {solv }}$ of bulk munition transferring into the aqueous phase shown in Table 1 . The solvation energy results line up within $2 \mathrm{kcal} \mathrm{mol}^{-1}$

Table 1. Aqueous Solvation Energy Relative to Amorphous Munition as Calculated by TI at a Temperature of $300 \mathrm{~K}^{a}$

$\begin{array}{lccc}\text { munition } & \Delta G_{\text {solv }}(\mathrm{kcal} / \mathrm{mol}) & \Delta G_{\text {solv }}(\mathrm{kcal} / \mathrm{g}) & \text { solubility }(\mathrm{g} / \mathrm{L}) \\ \text { DNAN } & -13 & -0.07 & 0.27^{41} \\ \mathrm{DNi}^{-} & -15^{b} & -0.15^{d} & 3370^{d, 42} \\ \mathrm{NH}_{4}^{+} & -14^{b} & & \\ \mathrm{nMNA} & -11 & -0.07 & <1^{43} \\ \mathrm{NQ} & -9 & -0.09 & 4.4^{44} \\ \mathrm{NTO} & -10 & -0.08 & 15^{45} \\ \mathrm{NTO}^{-} & -74^{c} & -0.57 & \\ \mathrm{RDX}^{\mathrm{TNT}} & -13 & -0.06 & 0.06^{46} \\ \mathrm{TNT} & -5 & -0.02 & 0.13^{47}\end{array}$

${ }^{a}$ First column is normalized by moles, whereas the second column is normalized by mass. Experimental solubility values from the literature at or near room temperature are included for comparison. ${ }^{b}$ Relative to equimolar ammonium dinitramide mixture. ${ }^{c}$ Relative to amorphous neutral NTO. ${ }^{d}[\mathrm{DNi}]^{-}\left[\mathrm{NH}_{4}\right]^{+}$treated as a single unit for comparison to experiment.

of values from literature where available. ${ }^{40}$ Although it should be mentioned that crystallographic energy changes from munition solidification are not taken into account here, the solvation energy data show that the ionic species will have a much higher propensity to be in solution as compared to the neutral compounds and enumerates the energetic contribution of aqueous partitioning. On a per-mass basis, the solvation energy from TI correlates with the log of solubility with an $R^{2}$ of 0.89 which helps to validate the simulation accuracy and increase confidence in the solvation energy values; these results are depicted in Figure 3.

Expanding beyond plain water to include the surface effects of droplets, the individual munition compounds have varied preference for the surface based on TI at the surface of a droplet compared to that within the bulk water. In general, the more highly charged species want as many waters around them as possible, whereas the aromatic compounds are most energetically favorable when they can expose half of the electrostatics to the gas phase. Table 2 highlights the percent

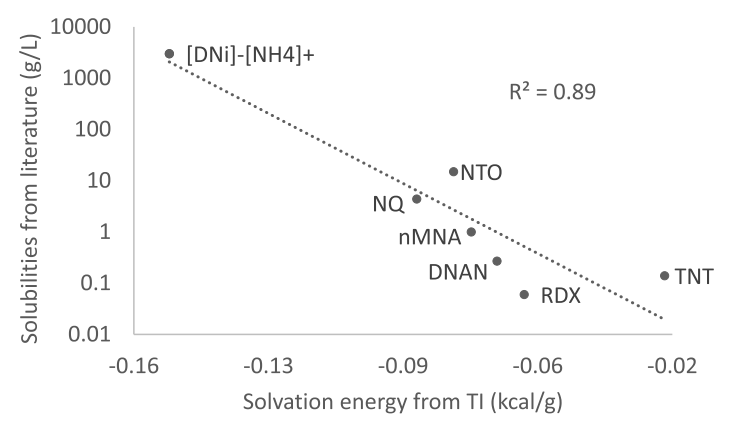

Figure 3. Plot showing the correlation between the solubilities available in the literature and the solvation energy calculated by TI for these munition compounds.

Table 2. Surface Preference of Munition Compounds

\begin{tabular}{lcc} 
munition & surface preference $(\%)$ & $\Delta G_{\text {surface }}(\mathrm{kcal} / \mathrm{mol})$ \\
$\mathrm{DNAN}^{-}$ & 90 & -5 \\
$\mathrm{DNi}^{-}$ & 2 & 9 \\
$\mathrm{NH}_{4}^{+}$ & 4 & 8 \\
$\mathrm{nMNA}$ & 96 & -8 \\
$\mathrm{NQ}$ & 46 & 0 \\
$\mathrm{NTO}$ & 38 & 1 \\
$\mathrm{NTO}^{-}$ & 4 & 8 \\
$\mathrm{RDX}$ & 20 & 3 \\
$\mathrm{TNT}$ & 64 & -1 \\
\hline
\end{tabular}

time spent at the surface and the energetic difference going from bulk solvation to surface solvation at the edge of the water droplet. The surface preference percentage is the percentage of time each ion spends at the surface of the droplet as calculated from the integration of the radial distribution functions to include the first solvation shell of water. These results are dependent upon the droplet size and should be considered as relative metrics only; further detail on this calculation can be found in the Supporting Information. The $\Delta G_{\text {surface }}$ values were calculated from TI with the munition at the water droplet interface, and the data correlate with aqueous solubility $\left(R^{2}=\right.$ 0.8 ) with higher surface preference indicating lower solubility. Variance from the trend arises particularly in TNT and RDX which despite their low solubility in water do not exhibit a strong preference for the surface of the water droplet. This can be explained by the strong intermolecular interactions in bulk TNT and RDX; on the basis of TI, results going from bulk TNT and $\mathrm{RDX}$ to gas phase require the addition of 40 and $54 \mathrm{kcal} / \mathrm{mol}$, respectively, which is significantly higher compared to the other munition compounds which average $28.5 \mathrm{kcal} / \mathrm{mol}$ for that transition. Conversely, the energy released in transition from gas phase to solvated aqueous phase is similar among all of the neutral munition compounds evaluated (14-24 kcal/mol). Solubility relates more closely to the energy difference between bulk and aqueous phases, whereas surface preference relates more closely to the energy difference between gas and aqueous phases. The relatively more favorable intermolecular interactions in TNT and RDX as compared to other munition compounds account for how overall solubility can be so low, and the individual molecules still not exhibit a strong preference for the surface of the water droplet.

Adding in the complexity of common ions in solution affects the diffusion of munition compounds. The average diffusion values taking into account the culmination of ions at the simulated concentrations were calculated by the Einstein 
relation-linear regression of the mean square displacement divided by 6 method $^{48}$ and are listed in Table 3. The cyclic

\section{Table 3. Diffusion Values Calculated for Munition} Compounds and Common Ions in Water ${ }^{a}$

\begin{tabular}{lclc} 
munition & diffusion $10^{-9} \mathrm{~cm}^{2} / \mathrm{s}$ & \multicolumn{1}{c}{ ion } & diffusion $10^{-9} \mathrm{~cm}^{2} / \mathrm{s}$ \\
DNAN & 5.7 & $\mathrm{Ca}^{2+}$ & 180 \\
$\mathrm{DNi}^{-}$ & 1.9 & $\mathrm{~K}^{+}$ & 540 \\
nMNA & 1.8 & $\mathrm{Cl}^{-}$ & 400 \\
NQ & 0.9 & $\mathrm{HCO}_{3}^{-}$ & 510 \\
NTO & 2.1 & $\mathrm{Mg}^{2+}$ & 110 \\
$\mathrm{NTO}^{-}$ & 1.0 & $\mathrm{Na}^{+}$ & 380 \\
$\mathrm{RDX}_{\mathrm{TNT}}$ & 5.2 & $\mathrm{SO}_{4}{ }^{2-}$ & 260 \\
& 4.2 & &
\end{tabular}

${ }^{a}$ Diffusion values are presented in units of $10^{-9} \mathrm{~cm}^{2} / \mathrm{s}$ and standard deviation of the predicted values is around $20 \%$ of the average value for each compound.

munition compounds (i.e., RDX, TNT, and DNAN) tend to show higher diffusion rates than the other munition compounds. By comparison, RDX, TNT, and DNAN bind water much less tightly than the other munition compounds as evidenced by broader, less-structured munition-water RDFs. Despite their relatively larger size, their lack of strong $\mathrm{H}$-bonding with the solvent may increase their apparent mobility. The molecules that form strong hydrogen bonds with the water diffuse much slower because the effective radii include the first solvation shell of waters in addition to the munition itself. Not surprisingly, the ions with smaller radii and a net charge of plus or minus two exhibit much slower diffusion than their singly-charged counterparts, as has been previously reported, ${ }^{49}$ and is in large part because of stronger water cluster formation surrounding the more densely charged ions.

The hydration shells surrounding each munition have been mapped out by spatial probability isosurfaces (volmaps) and $\mathrm{RDF}$ for each munition in the bulk natural water model and near the surface of a water droplet. Isosurfaces were rendered in visual molecular dynamics from the complete trajectories of each system mapping the average probability of finding a solvent species in any specific location relative to the munition. The shaded areas represent regions of space that have a higher than average chance of containing the water molecule centers. Changes to the preferred water distributions surrounding the munition were calculated as a difference compared to the water distribution of munition in pure bulk water. The relative disruptive impact of ions and surfaces to the hydration shell is plotted in Figure 4. The hydration shell of the aromatic compounds (i.e., nMNA, DNAN, and TNT) exhibits a much higher disruption by water surfaces than the other munition compounds. This correlates strongly with the surface preference (Table 2) wherein these molecules are asymmetrically solvated when near the water's surface. Conversely, they are less impacted by ions in solution than NQ RDX, and NTO. The ionic strength of water solvating these munitions is hypothesized to play a greater role in the fate and transport of NQ, RDX, and NTO as compared to the DNAN, nMNA, and TNT.

Using umbrella sampling to get the PMFs for each munitionion pair, we can calculate the average time spent with each ion and how long the average interaction lasts (Table 4). The average time spent interacting is calculated as a Boltzmann population of states weighted by the well depth of the PMF and concentration of the solutes. Figure 5 depicts the shape and key

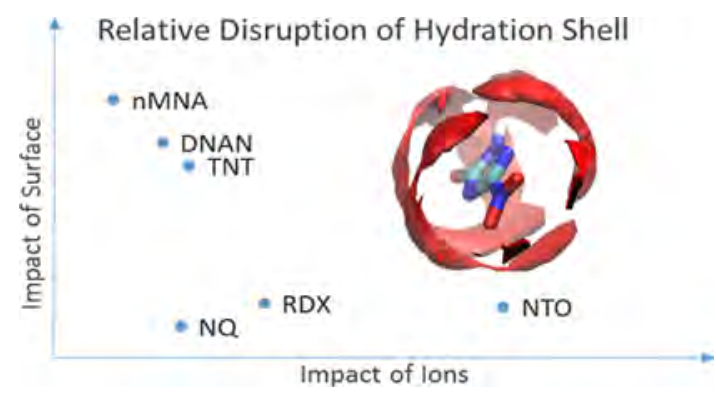

Figure 4. Depiction of the relative disruption to the hydration shell surrounding munition compounds caused by the munition proximity either to the surface of the water or to various ions in solution relative to pure water.

Table 4. Data Showing How Long Each Munition-Ion Interaction Lasts on Average Based on Integration of the PMF

\begin{tabular}{lrrrrrrrr}
$\begin{array}{l}\text { residence } \\
\text { time (ns) }\end{array}$ & $\mathrm{NH}_{4}^{+}$ & $\mathrm{Ca}^{2+}$ & \multicolumn{1}{c}{$\mathrm{K}^{+}$} & $\mathrm{Cl}^{-}$ & $\mathrm{HCO}_{3}^{-}$ & $\mathrm{Mg}^{2+}$ & $\mathrm{Na}^{+}$ & $\mathrm{SO}_{4}{ }^{2-}$ \\
$\mathrm{DNAN}$ & 0.5 & 7.6 & 0.8 & 2.3 & 2.2 & 0.7 & 0.7 & 6.7 \\
$\mathrm{DNi}^{-}$ & 1.8 & 0.1 & 0.8 & 1.9 & 2.1 & 3.0 & 0.6 & 2.3 \\
$\mathrm{NH}_{4}^{+}$ & 0.5 & 15.5 & 4.4 & 0.8 & 1.1 & 16.8 & 3.2 & 0.2 \\
$\mathrm{nMNA}$ & 1.0 & 8.8 & 0.3 & 8.3 & 4.0 & 1.7 & 0.1 & 0.5 \\
$\mathrm{NQ}$ & 2.3 & 8.6 & 4.3 & 3.7 & 1.9 & 4.2 & 2.2 & 2.3 \\
$\mathrm{NTO}$ & 5.8 & 6.8 & 1.9 & 1.6 & 1.3 & 6.3 & 0.4 & 2.8 \\
$\mathrm{NTO}^{-}$ & 3.9 & 0.1 & 1.2 & 2.1 & 0.1 & 9.7 & 2.0 & 3.9 \\
$\mathrm{RDX}$ & 9.3 & 3.3 & 6.6 & 3.8 & 2.6 & 5.3 & 3.3 & 2.1 \\
$\mathrm{TNT}$ & 5.9 & 14.2 & 3.4 & 1.7 & 0.1 & 7.6 & 4.4 & 2.1 \\
\hline
\end{tabular}

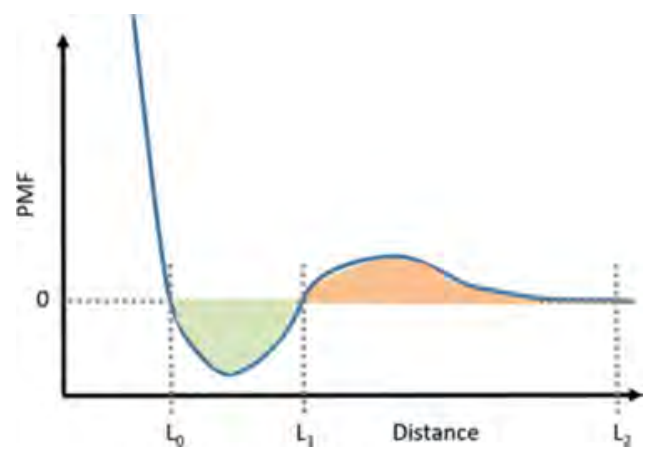

Figure 5. Generalized PMF for ion separation distance with annotations.

intersects of a general PMF between two species in solution. The integration of the PMF, eq $1,^{50}$ can be used to calculate the average residence time or average duration of each munition-ion interaction

$$
\begin{aligned}
\tau & =\int_{L_{0}}^{L_{1}} \frac{1}{v} \mathrm{e}^{(-E(L) / R T)} \mathrm{d} L \times \int_{L_{1}}^{L_{2}} \frac{1}{\lambda} \mathrm{e}^{(E(L) / R T)} \mathrm{d} L \\
& =\frac{1}{2 D} \int \mathrm{e}^{(\operatorname{abs}(E(L)) / R T)} \mathrm{d} L
\end{aligned}
$$

where $L$ is the munition-ion separation distance, $v$ is the mean velocity, $E(L)$ is the energy of the PMF at that separation distance, $\lambda$ is the mean-free path, $R$ is the universal gas constant, and $T$ is the temperature. The cutoffs for integration over the separation distance are also displayed in Figure 5, where $L_{0}$ is the start of the valley, $L_{1}$ is the end of the valley and start of the peak, and $L_{2}$ is insensitive in definition as long as its occurs after the PMF tails to 0 . 
PMFs for each munition-ion pair are included in the Supporting Information (Figures S1-S9). For purposes of this calculation, the mean-free path and velocity terms were combined to form the diffusion coefficient, $D$, and a factor of 2 as shown in the right-hand side of eq 1 . Diffusion coefficients were calculated from $\mathrm{MD}$ simulations. In general, slower diffusivity, deeper energy wells, and taller barriers all increase the length of time ion and munition spend in proximity each interaction occurrence. The residence time data are shown in Table 4.

The results in Table 4 relate not only how the munition compound transports but also the opportunities for degradation to be catalyzed through ionic interactions. $\mathrm{Mg}^{2+}$ and $\mathrm{Ca}^{2+}$ exhibit some of the longest residence times of these selected ions and that is largely due to the relatively large energy barrier from separating them from munition compounds. Consequently, even though $\mathrm{Mg}^{2+}$ and $\mathrm{Ca}^{2+}$ are typically lower concentration in natural water than say $\mathrm{Na}^{+}$and $\mathrm{HCO}_{3}{ }^{-}$, the former may contribute more than the latter to potential ion-mediated degradation pathways.

In order to approximate the relative degradation enhancement caused by each ion for each munition compound, a series of 20 short ( $2 \mathrm{~ns}$ each) independent QM/MM simulations were performed for a total of $40 \mathrm{~ns}$ of accelerated QM/MM simulation for each munition-ion pair. The QM region included the munition, ion, and 6 closest waters. There were no intramolecular QM/MM boundaries, and the boundary was adaptive to the location and shape of the included molecules and ions. Degradation is more likely to occur at higher boost potentials because the acceleration method lowers potential energy barriers between states making bond breakage and formation much more probable. We hypothesize that a Boltzmann treatment of the additional energy added to each system in accelerated QM/MM will provide a qualitative means of predicting changes to the degradation propensity caused by various ionic exposures. Accordingly, the simulations were weighted by a Boltzmann factor of the boost applied at a temperature of $300 \mathrm{~K}$ and characterized by whether or not there was any change in the bonding topology of the munition during each of the 20 short QM/MM simulations for each munition ion pair. In other words, the propensity for degradation was estimated by eq 2

$$
P_{\text {degrade }}=\sum_{i=1}^{20} B_{i} \times \mathrm{e}^{-E_{\mathrm{bi}} / R T} / \sum_{i=1}^{20} \mathrm{e}^{-E_{\mathrm{bi}} / R T}
$$

where $B_{i}$ is the binary result of that iteration of the simulation (i.e., 1 if a change in bonding topology occurred, otherwise 0 ), $E_{\mathrm{bi}}$ is the boost energy of that iteration, $R$ is the universal gas constant, and $T$ is the temperature. The resulting propensities for ion-mediated degradation are depicted in Figure 6.

Interactions of the munition compounds with $\mathrm{Cl}^{-}$and $\mathrm{SO}_{4}{ }^{2-}$ were the most likely to initiate degradation. The neutral form of NTO readily donated a proton to solution in every case with a slight stabilization effect observed with $\mathrm{Ca}^{2+}$ and $\mathrm{HCO}_{3}{ }^{-}$ions. Within proximity of either of these two ions, the structure of NTO remained intact for a few of the simulations. $\mathrm{NTO}^{-}$was also observed to undergo proton transfers both with and without the anions present but to a lesser degree than the neutral NTO. These predictions agree closely with the findings of McAlexander et al. ${ }^{51}$ who show using DFT that the $\mathrm{Cl}^{-}$and $\mathrm{SO}_{4}{ }^{2-}$ anions were especially conducive to the aqueous degradation of munition compounds. They also observed

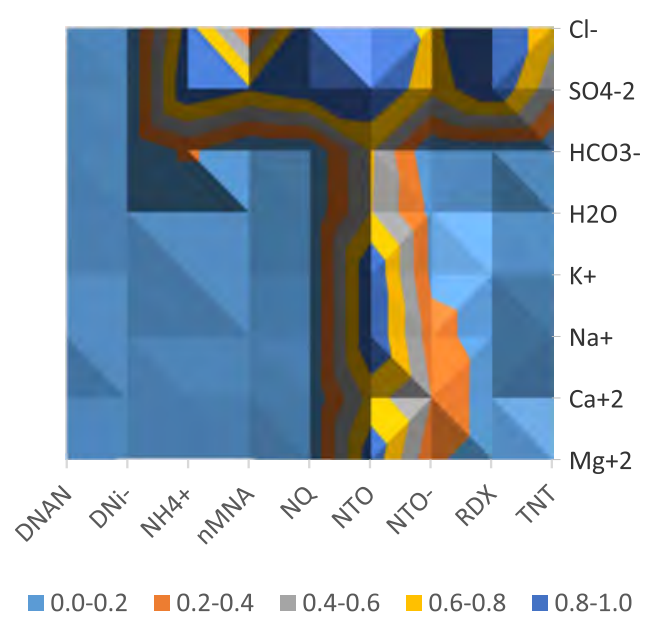

Figure 6. Normalized heat map of the propensity for the degradation of munition/ion pairs. $Y$-axis ions are arranged by charge density from strongest negative to strongest positive charge density.

spontaneous proton transfer in the NTO species. ${ }^{51,52}$ The munition compounds with aromatic rings (i.e., DNAN, nMNA, and TNT) were among the least likely to degrade even with high boost potentials applied to the system. This trend lines up with experimental observations wherein environmental mineralization of the aromatic compounds tends to take much longer than nonaromatic compounds.

Compared to DFT methods, the QM/MM study reported here is less computationally and labor intensive and allows exploration of degradation pathways without a priori knowledge of the mechanisms. This QM/MM method generates degradation mode predictions and samples thousands of potential ion-munition-water configurations rapidly. Once the likely degradation modes are identified, validation and evaluation of the energetics with a higher level of quantum theory will proceed with much less computational and labor intensity as compared to searching all of the potential reaction space with quantum mechanical methods.

\section{CONCLUSIONS}

This research demonstrates the water model framework for determining the relative impact of individual ions on interactions and reactions in natural water compositions. To aid in the prediction of fate and transport of several prevalent munition compounds, the surface preference and solvation energies were calculated for each compound. A QM/MM method to identify possible degradation pathways without a priori knowledge was implemented. Data included diffusion constants, residence times, interaction frequencies, and changes in susceptibility to the degradation of the munition for each compound-ion pair. It was found that $\mathrm{SO}_{4}{ }^{2-}$ and $\mathrm{Cl}^{-}$ions contribute strongest to the fate and transport of the investigated munition compounds, and those ion concentrations should be prioritized above other ions for addition into the environmental models that predict fate and transport of munition compounds.

\section{ASSOCIATED CONTENT}

The Supporting Information is available free of charge on the ACS Publications website at DOI: 10.1021/acs.jpca.9b01742. 
PMF calculated for IM-ION pairs using umbrella sampling for insensitive munition: DNAN, DNi-, nMNA, NQ NTO, $\mathrm{NTO}^{-}$, RDX, and TNT and calculation of the percent surface preference (PDF)

\section{ACKNOWLEDGMENTS}

The authors would like to acknowledge editing and proof reading by colleagues Dr. Glen Jenness and Dr. Harley McAlexander for their aid in the preparation of this manuscript. The use of trade, product, or firm names in this report is for descriptive purposes only and does not imply endorsement by the U.S. Government. The tests described and the resulting data presented herein, unless otherwise noted, were obtained from research conducted under the Environmental Quality Technology Program of the United States Army Corps of Engineers and the Environmental Security Technology Certification Program of the Department of Defense by the USAERDC. Permission was granted by the Chief of Engineers to publish this information.

\section{ABBREVIATIONS}

\begin{tabular}{|c|c|}
\hline DNAN & 2,4-dinitroanisole \\
\hline$[\mathrm{NH} 4]^{+}[\mathrm{DNi}]^{-}$ & ammonium dinitramide \\
\hline nMNA & $N$-methyl-p-nitroaniline \\
\hline NQ & 1-nitroguanidine \\
\hline NTO & 3-nitro-1,2,4-triazol-5-one (neutral form) \\
\hline $\mathrm{NTO}^{-}$ & $\begin{array}{l}\text { conjugate base of NTO (anionic/deproto- } \\
\text { nated form) }\end{array}$ \\
\hline PMF & potential of mean force \\
\hline $\mathrm{RDF}$ & radial distribution function \\
\hline $\mathrm{RDX}$ & 1,3,5-trinitro-1,3,5-triazinane \\
\hline TNT & 2,4,6-trinitrotoluene \\
\hline
\end{tabular}

\section{REFERENCES}

(1) Isler, J. The Transition to Insensitive Munitions(IM). Propellants, Explos., Pyrotech. 1998, 23, 283-291.

(2) Badgujar, D. M.; Talawar, M. B.; Asthana, S. N.; Mahulikar, P. P. Advances in Science and Technology of Modern Energetic Materials: An Overview. J. Hazard. Mater. 2008, 151, 289-305.

(3) Walsh, M. R.; Walsh, M. E.; Ramsey, C. A.; Thiboutot, S.; Ampleman, G.; Diaz, E.; Zufelt, J. E. Energetic Residues from the Detonation of IMX-104 Insensitive Munitions. Propellants, Explos., Pyrotech. 2014, 39, 243-250.

(4) Reddy, G.; Song, J.; Kirby, P.; Lent, E. M.; Crouse, L. C. B.; Johnson, M. S. Genotoxicity Assessment of an Energetic Propellant Compound, 3-Nitro-1,2,4-Triazol-5-One (NTO). Mutat. Res., Genet. Toxicol. Environ. Mutagen. 2011, 719, 35-40.

(5) Kennedy, A. J.; Lounds, C. D.; Melby, N. L.; Laird, J. G.; Winstead, B.; Brasfield, S. M.; Johnson, M. S. Development of Environmental Health Criteria for Insensitive Munitions: Aquatic Ecotoxicological Exposures Using, 2013.
(6) Olivares, C. I.; Sierra-Alvarez, R.; Abrell, L.; Chorover, J.; Simonich, M.; Tanguay, R. L.; Field, J. A. Zebrafish Embryo Toxicity of Anaerobic Biotransformation Products from the Insensitive Munitions Compound 2,4-Dinitroanisole. Environ. Toxicol. Chem. 2016, 35, 2774-2781.

(7) Linker, B. R.; Khatiwada, R.; Perdrial, N.; Abrell, L.; SierraAlvarez, R.; Field, J. A.; Chorover, J. Adsorption of novel insensitive munitions compounds at clay mineral and metal oxide surfaces. Environ. Chem. 2015, 12, 74-84.

(8) Simůnek, J.; van Genuchten, M. T. Modeling Nonequilibrium Flow and Transport Processes Using HYDRUS. Vadose Zone J. 2008, 7, 782 .

(9) Dortch, M. S.; Johnson, B. E.; Gerald, J. A.; Zhang, Z.; Simmons, A. P. Proof-of-Concept Application of Tier 2 Modeling Approach within the Training Range Environmental Evaluation and Characterization System Proof-of-Concept Application of Tier 2 Modeling Approach within the Training Range Environmental Evaluation and Charact, 2011.

(10) Cuddy, M. F.; Poda, A. R.; Chappell, M. A. Estimations of Vapor Pressures by Thermogravimetric Analysis of the Insensitive Munitions IMX-101, IMX-104, and Individual Components. Propellants, Explos., Pyrotech. 2014, 39, 236-242.

(11) Sokkalingam, N.; Potoff, J. J.; Boddu, V. M.; Maloney, S. W. Prediction of Environmental Impact of High-Energy Materials With Atomistic Computer Simulations. Wayne State Univ. Detroit MI Department of Chemical Engineering \& Materials Science, 2008, No. November; pp 1-7.

(12) Richard, T.; Weidhaas, J. Dissolution, Sorption, and Phytoremediation of IMX-101 Explosive Formulation Constituents: 2,4 Dinitroanisole (DNAN), 3-Nitro-1,2,4-Triazol-5-One (NTO), and Nitroguanidine. J. Hazard. Mater. 2014, 280, 561-569.

(13) Koutsospyros, A.; Pavlov, J.; Fawcett, J.; Strickland, D.; Smolinski, B.; Braida, W. Degradation of High Energetic and Insensitive Munitions Compounds by $\mathrm{Fe} / \mathrm{Cu}$ Bimetal Reduction. J. Hazard. Mater. 2012, 219-220, 75-81.

(14) Dontsova, K.; Brusseau, M.; Arthur, J.; Mark, N.; Taylor, S.; Pesce-rodriguez, R.; Brusseau, M.; Arthur, J.; Mark, N.; Walsh, M.; et al. Dissolution of NTO, DNAN and Insensitive Munitions Formulations and Their Fates in Soils. Tech. Rep. 2014, 32-47. https://apps.dtic. $\mathrm{mil} / \mathrm{dtic} / \mathrm{tr} /$ fulltext/u2/a609594.pdf.

(15) Hawari, J.; Monteil-rivera, F.; Perreault, N. N.; Halasz, A.; Paquet, L.; Radovic-hrapovic, Z.; Deschamps, S.; Thiboutot, S.; Ampleman, G. Environmental fate of 2,4-dinitroanisole (DNAN) and its reduced products. Chemosphere 2015, 119, 16-23.

(16) Salter-Blanc, A. J.; Bylaska, E. J.; Ritchie, J. J.; Tratnyek, P. G. Mechanisms and Kinetics of Alkaline Hydrolysis of the Energetic Nitroaromatic Compounds 2,4,6-Trinitrotoluene (TNT) and 2,4Dinitroanisole (DNAN). Environ. Sci. Technol. 2013, 47, 6790-6798.

(17) Spain, J. C. Biodegradation of Nitroaromatic Compounds. Annu. Rev. Microbiol. 1995, 49, 523-555.

(18) Rice, B. M. Multiscale Modeling of Energetic Materials: Easy to Say, Harder to Do. AIP Conf. Proc. 2012, 1426, 1241-1246.

(19) Case, D. A.; Berryman, J. T.; Betz, R. M.; Cerutti, D. S.; Cheatham, T. E., III; Darden, T. A.; Duke, R. E.; Giese, T. J.; Gohlke, H.; Goetz, A. W.; Homeyer, N.; Izadi, S.; Janowski, P.; Kaus, J.; Kovalenko, A.; Lee, T. S.; LeGrand, S.; Li, P.; Luchko, T.; Luo, R.; Madej, B.; Merz, K. M.; Monard, G. Amber Molecular Dynamics. University of California: San Francisco 2016.

(20) Sprenger, K. G.; Jaeger, V. W.; Pfaendtner, J. The General AMBER Force Field (GAFF) Can Accurately Predict Thermodynamic and Transport Properties of Many Ionic Liquids. J. Phys. Chem. B 2015, $119,5882-5895$.

(21) Wang, J.; Wolf, R. M.; Caldwell, J. W.; Kollman, P. A.; Case, D. A. Development and Testing of a General AMBER Force Field. J. Comput. Chem. 2004, 25, 1157-1174.

(22) Wang, J.; Wang, W.; Kollman, P. A.; Case, D. A. Automatic Atom Type and Bond Type Perception in Molecular Mechanical Calculations. J. Mol. Graphics Modell. 2006, 25, 247-260.

(23) Møller, C.; Plesset, M. S. Note on an Approximation Treatment for Many-Electron Systems. Phys. Rev. 1934, 46, 618-622. 
(24) Dunning, T. H., Jr. Gaussian basis sets for use in correlated molecular calculations. I. The atoms boron through neon and hydrogen. J. Chem. Phys. 1989, 90, 1007-1023.

(25) Frisch, M. J.; Trucks, G. W.; Schlegel, H. B.; Scuseria, G. E.; Robb, M. A.; Cheeseman, J. R.; Scalmani, G.; Barone, V.; Petersson, G. A.; Nakatsuji, H.; Li, X.; Caricato, M.; Marenich, A. V.; et al. Gaussian16, Revision B.01; Gaussian Inc.: Wallingford CT, 2016.

(26) Zhang, Y.; Maginn, E. J. A Simple AIMD Approach to Derive Atomic Charges for Condensed Phase Simulation of Ionic Liquids. J. Phys. Chem. B 2012, 116, 10036-10048.

(27) Sambasivarao, S. V.; Acevedo, O. Development of OPLS-AA Force Field Parameters for 68 Unique Ionic Liquids. J. Chem. Theory Comput. 2009, 5, 1038-1050.

(28) Schutt, T. C.; Bharadwaj, V. S.; Hegde, G. A.; Johns, A. J.; Mark Maupin, C. In silico insights into the solvation characteristics of the ionic liquid 1-methyltriethoxy-3-ethylimidazolium acetate for cellulosic biomass. Phys. Chem. Chem. Phys. 2016, 18, 23715-23726.

(29) Bharadwaj, V. S.; Schutt, T. C.; Ashurst, T. C.; Maupin, C. M. Elucidating the Conformational Energetics of Glucose and Cellobiose in Ionic Liquids. Phys. Chem. Chem. Phys. 2015, 17, 10668-10678.

(30) Horn, H. W.; Swope, W. C.; Pitera, J. W.; Madura, J. D.; Dick, T. J.; Hura, G. L.; Head-Gordon, T. Development of an Improved FourSite Water Model for Biomolecular Simulations: TIP4P-Ew. J. Chem. Phys. 2004, 120, 9665-9678.

(31) Jorgensen, W. L.; Chandrasekhar, J.; Madura, J. D.; Impey, R. W.; Klein, M. L. Comparison of Simple Potential Functions for Simulating Liquid Water. J. Chem. Phys. 1983, 79, 926-935.

(32) Martínez, L.; Andrade, R.; Birgin, E. G.; Martínez, J. M. PACKMOL: A Package for Building Initial Configurations for Molecular Dynamics Simulations. J. Comput. Chem. 2009, 30, 21572164.

(33) Darden, T.; York, D.; Pedersen, L. Particle mesh Ewald: An N. $\log (\mathrm{N})$ method for Ewald sums in large systems. J. Chem. Phys. 1993, 98, 10089-10092.

(34) Pastor, R. W.; Brooks, B. R.; Szabo, A. An Analysis of the Accuracy of Langevin and Molecular Dynamics Algorithms. Mol. Phys. 1988, 65, 1409-1419.

(35) Van Gunsteren, W. F.; Berendsen, H. J. C. A LEAP-FROG ALGORITHM FOR STOCHASTIC DYNAMICS. Mol. Simul. 1988, $1,173-185$.

(36) Miyamoto, S.; Kollman, P. A. SETTLE: An Analytical Version of the SHAKE and RATTLE Algorithm for Rigid Water Models. J. Comput. Chem. 1992, 13, 952-962.

(37) Kumar, S.; Rosenberg, J. M.; Bouzida, D.; Swendsen, R. H.; Kollman, P. A. THE weighted histogram analysis method for freeenergy calculations on biomolecules. I. The method. J. Comput. Chem. 1992, 13, 1011-1021.

(38) Hamelberg, D.; Mongan, J.; McCammon, J. A. Accelerated Molecular Dynamics: A Promising and Efficient Simulation Method for Biomolecules. J. Chem. Phys. 2004, 120, 11919-11929.

(39) Miao, Y.; Feher, V. A.; McCammon, J. A. Gaussian Accelerated Molecular Dynamics: Unconstrained Enhanced Sampling and Free Energy Calculation. J. Chem. Theory Comput. 2015, 11, 3584-3595.

(40) Sitkoff, D.; Sharp, K. A.; Honig, B. Accurate Calculation of Hydration Free Energies Using Macroscopic Solvent Models. J. Phys. Chem. 1994, 98, 1978-1988.

(41) Boddu, V. M.; Abburi, K.; Maloney, S. W.; Damavarapu, R. Thermophysical Properties of an Insensitive Munitions Compound, 2,4-Dinitroanisole. J. Chem. Eng. Data 2008, 53, 1120-1125.

(42) Wingborg, N.; de Flon, J.; Johnson, C.; Whitlow, W. Green Propellants Based on ADN. Advances in Spacecraft Technologies, 2008 2008, No. 2, 5-8.

(43) ORR; NOAA; NOS. Cameo Chemicals: N-METHYL-4NITROANILINE.

(44) Yalkowsky, S. H.; He, Y. Handbook of Aqueous Solubility Data: An Extensive Compilation of Aqueous Solubility Data for Organic Compounds Extracted from the AQUASOL DATAbASE; CRC Press LLC: Boca Raton, FL, 2003.
(45) Braida, W.; Wazne, M.; Pavlov, J.; Kalomoiri, A.; Koutsospyros, A.; Balok, V. Dissolution of Nitrotriazolone (NTO) from Insensitive Munitions. Conference: In Proceedings of Protection and Restoration of the Environment XI; Thessaloniki, Greece, 2012.

(46) Abadin, H.; Smith, C.; Ingerman, L.; Llados, F. T.; Barber, L. E.; Plewak, D.; Diamond, G. L. Toxicological Profile for RDX; Technical Report. US Department of Health \& Human Services 2012, pp 1-215.

(47) Kalderis, D.; Juhasz, A.; Boopathy, R.; Comfort, S. Soils Contaminated with Explosives: Environmental Fate and Evaluation of State-Ofthe-Art Remediation Processes (IUPAC Technical Report). Pure Appl. Chem. 2011, 83 (7), 1407-1484.

(48) Case, D. A.; Cerutti, D. S.; Cheatham, T. E.; Darden, T. A., III; Duke, R. E.; Giese, T. J.; Gohlke, H.; Goetz, A. W.; Greene, D.; Homeyer, N.; Izadi, S.; Kovalenko, A.; Lee, T. S.; LeGrand, S.; Li, P.; Lin, C.; Liu, J.; Luchko, T.; Luo, R.; Mermelstein, D.; Merz, K. M.; Monard, G.; Monard, H.; Nguyen, I.; Omelyan, A.; Onufriev, F.; Pan, R.; Qi, D. R.; Roe, A.; Roitberg, C.; Sagui, C. L.; et al. Amber 2016 Manual; University of California: San Francisco, 2017.

(49) Sato, H.; Yui, M.; Yoshikawa, H. Two Phase Pressure Drop Multipliers and ICE Technique Applied in a Multibubble Slug Ejection Model. J. Nucl. Sci. Technol. 1996, 33, 950-955.

(50) Marklund, E. G.; Mahmutovic, A.; Berg, O. G.; Hammar, P.; van der Spoel, D.; Fange, D.; Elf, J. Transcription-Factor Binding and Sliding on DNA Studied Using Micro- and Macroscopic Models. Proc. Natl. Acad. Sci. U.S.A. 2013, 110, 19796-19801.

(51) McAlexander, H. R.; Shukla, M. K. Interactions of Insensitive Munitions Compounds with Cations and Anions in Water Solution: An Ab Initio Approach. In submission, 2018.

(52) Shukla, M. K.; Hill, F. Dissociative Adsorption of 5-Nitro-2,4dihydro-3H-1,2,4-triazol-3-one (NTO) on Aluminum-Terminated (0001) Surface of $\alpha$-Alumina As Predicted from Plane-Wave Density Functional Theory. J. Phys. Chem. C 2014, 118, 310-319. 


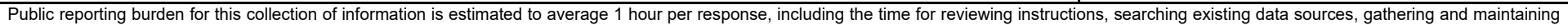

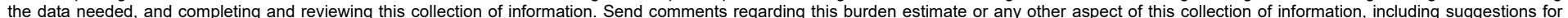

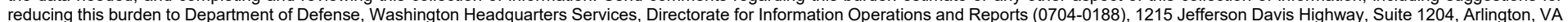

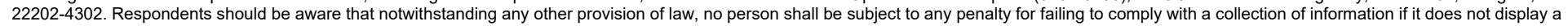
currently valid OMB control number. PLEASE DO NOT RETURN YOUR FORM TO THE ABOVE ADDRESS.
1. REPORT DATE (DD-MM-YYYY)
August 2021

\section{TITLE AND SUBTITLE}

Predicting the Impact of Aqueous Ions on Fate and Transport of Munition Compounds in the Environment

\section{AUTHOR(S)}

Timothy C. Schutt and Manoj K. Shukla
3. DATES COVERED (From - To)

5a. CONTRACT NUMBER

5b. GRANT NUMBER

5c. PROGRAM ELEMENT NUMBER

5d. PROJECT NUMBER

5e. TASK NUMBER

5f. WORK UNIT NUMBER

8. PERFORMING ORGANIZATION REPORT NUMBER

ERDC/EL MP-21-5

10. SPONSOR/MONITOR'S ACRONYM(S)

USACE

11. SPONSOR/MONITOR'S REPORT NUMBER(S)

\section{DISTRIBUTION / AVAILABILITY STATEMENT}

Approved for public release; distribution is unlimited.

\section{SUPPLEMENTARY NOTES}

This article was originally published in the Journal of Physical Chemistry on 9 May 2019.

This study was conducted for the U.S. Army Corps of Engineers (USACE) under the Environmental Quality Technology Program of the United States Army Corps of Engineers and the Environmental Security Technology Certification Program (ESTCP) of the Department of Defense.

\section{ABSTRACT}

A model framework for natural water has been developed using computational chemistry techniques to elucidate the interactions between solvated munition compounds and eight common ions in naturally occurring water sources. The interaction energies, residence times, coordination statistics, and surface preferences of nine munition related compounds with each ion were evaluated. The propensity of these interactions to increase degradation of the munition compound was predicted using accelerated replica QM/MM simulations. The degradation prediction data qualitatively align with previous quantum mechanical studies. The results suggest that primary ions of interest for fate and transport modeling of munition compounds in natural waters may follow the relative importance of $\mathrm{SO}_{42}, \mathrm{Cl}_{-} \gg \mathrm{HCO}_{3}-, \mathrm{Na}_{+}, \mathrm{Mg}_{2+}>\mathrm{Ca}_{2+}, \mathrm{K}_{+}, \mathrm{and} \mathrm{NH}_{4+}$.

\section{SUBJECT TERMS}

Explosives, Military-Residues; Explosives, Military--Environmental aspects; Water--Ions

\section{SECURITY CLASSIFICATION OF:}

\section{a. REPORT}

Unclassified

\section{b. ABSTRACT \\ Unclassified}

c. THIS PAGE

Unclassified
17. LIMITATION OF ABSTRACT

UU
18. NUMBER OF PAGES

12 19a. NAME OF RESPONSIBLE PERSON

19b. TELEPHONE NUMBER (include area code) 